\title{
Advances in Aerial Application Technologies and Decision Support for Integrated Pest Management
}

\author{
Ian M. McLeod ${ }^{1}$, Christopher J. Lucarotti2,3, ${ }^{,}$, Chris R. Hennigar ${ }^{3}$, \\ David A. MacLean ${ }^{3}$, A. Gordon L. Holloway4, \\ Gerald A. Cormier ${ }^{1}$ and David C. Davies ${ }^{1}$ \\ ${ }^{1}$ Forest Protection Limited, Fredericton International Airport, Lincoln, \\ ${ }^{2}$ Natural Resources Canada, Canadian Forest Service - \\ Atlantic Forestry Centre, Fredericton, \\ ${ }^{3}$ Faculty of Forestry and Environmental Management and \\ ${ }^{4}$ Department of Mechanical Engineering, The University of New Brunswick, Fredericton
}

Canada

\section{Introduction}

The first aerial applications of a pesticide against forest insect pests in Canada used calcium arsenate to protect forest stands from defoliation by the spruce budworm (Choristoneura fumiferana). The program was first conducted in Nova Scotia in 1927, and then in Ontario in 1928 and 1929 (Randall, 1975). There were few developments during the 1930s, but World War II and the need to protect military personnel from mosquitoes helped establish aerial spray techniques using a variety of aircraft (Randall, 1975). Extensive outbreaks of spruce budworm populations in Canada were countered by aerial application of DDT (dichlorodiphenyl-trichloro-ethane) in 1944 in Ontario (Howse \& Sippell, 1975), then in 1952 in Quebec (Blais et al., 1975) and New Brunswick (Miller \& Kettela, 1975).

Insecticidal powders were first released from hoppers mounted directly on the aircraft, but liquid formulations of pesticides led to the development of gravity-flow, open-pipe systems, boom and nozzle systems and rotary atomizers variously distributed on the aircraft fuselage and wings (Randall, 1975). In the 1950s and 1960s, hydraulic boom and nozzle systems were used predominantly in forestry, but with research suggesting that $100-\mu \mathrm{m}$ and smaller droplets are more effective against forest pest insects, rotary atomizers are now favoured (Weisner, 1995).

Aircraft guidance and direction to spray blocks was initially accomplished using topographic maps and features on the landscape. In the case of small blocks, helium-filled balloons, deployed from the ground, were sometimes used to mark the corners. Forest Protection Limited (FPL) (Lincoln, New Brunswick) was the first to use "spotter" aircraft that communicated information on block location and boundaries to spray pilots in flight (Flieger, 1964). Electronic guidance systems for the positioning of spray aircraft were first 
used in 1959 (Randall, 1975), and the availability of satellite-based, global positioning system (GPS) technologies onboard aircraft immensely improved aircraft guidance and navigation.

Since its incorporation in 1952, FPL has been a leader in the development of technologies to increase the efficacy, accuracy and safety of aerial application and fire control operations. In January 2007, FPL - in partnership with AG-NAV Inc., BioAtlantech, the Canadian Forest Service (CFS), Sylvar Technologies Inc., and the University of New Brunswick (UNB), received a 5-year grant from the Atlantic Innovation Fund (AIF) of the Atlantic Canada Opportunities Agency (ACOA) to further develop aerial application technologies and baculoviruses for use in controlling forest insect pests. In this review, we describe progress on the research that has led to the Accuair ${ }^{\mathrm{TM}}$ suite of aerial application technologies and services. For more detailed information on aerial application practices and technologies generally, readers are directed to articles referenced in this review (e.g., Payne, 1995; Weisner, 1995; Kilroy et al., 2003, Mierzejewski et al., 2007).

\section{The development of Accuair ${ }^{\mathrm{TM}}$ technologies}

\subsection{Overview}

Accuair $^{\mathrm{TM}}$ is the brand for an integrated system that is capable of increasing aerial spray program efficiency. One component is the Accuair Aerial Management System (AMS) - an onboard guidance, navigation and control system that optimizes spray lines on a treatment block to compensate for changes in wind conditions and aircraft altitude at the time of spraying. The AMS uses spray droplet size information gathered from a second component, the Accuair Wind Tunnel. Droplet size is influenced by a host of factors whose effects cannot be easily predicted or generalized. A wind tunnel provides a means of measuring droplet sizes under a set of conditions that replicate actual operational situations. With these data from the wind tunnel, the AMS drift simulation software can develop more realistic predictions. Accuair ${ }^{\mathrm{TM}}$ Forest Protection Optimization System (ForPRO), the third component, is a planning software that uses forest stand information and risk factor overlays to identify areas within a region that are most in need of protection from forest insect pests.

\subsection{Aerial management systems}

The AMS that led to Accuair ${ }^{\mathrm{TM}}$ had its beginning in the early 1990s with the availability of inexpensive GPS and other sensing equipment that could be easily installed and used on spray aircraft. As early as 1991, the usefulness of newly available radar altimeters for determining of aircraft altitude above the ground and forest canopy was recognized (Mickle \& Robinson, 1991). Knowledge of aircraft altitude above ground is a critical parameter in predicting spray drift, and such data are not provided by standard aircraft altimeters that use air pressure to determine height above sea level. A summary by Davies (1994) described trials of a system that made it possible to log flight data-including aircraft altitude and attitude, boom on/off functions, atomizer rotational speed, and application rate-that allowed managers to visualize these parameters on a computer interface, assess spray quality and make improvements. At the same time, Riley (1994) reported on work that had examined factors affecting the deposition and drift of pesticide sprays, including droplet size, atomizer configuration, influence of evaporation and product volatility, release height 
and atmospheric turbulence. Using the insights from these reports, Mickle $(1998,1999)$ used geographic information systems (GIS) and GPS-based guidance systems to improve the accuracy of aircraft positioning relative to the spray block. Wind data were also recorded on spotter aircraft using an Aircraft-Integrated Meteorological Measurement System (AIMMS10; Aventech Research Inc., Barrie, ON) to obtain wind speed and direction at the altitude of the aircraft and at the time of spraying. In addition, a spray droplet dispersion model was used to determine optimal droplet size distributions to deliver a maximum number of droplets of pesticide to the target area for a variety of spray strategies. It was concluded that this practice delivered a more uniform application because it compensated for low upwind deposition as a result of wind-driven drift (Mickle, 1998, 1999). A second conclusion was that better efficacy was achieved if smaller droplets were used, as drifting sprays inherently give more uniform coverage of the target area. This second conclusion agreed with the report by Picot (1994) describing simulations of spray drift using a dispersion model where spray efficacy was evaluated based on delivering the maximum number of droplets to a block. It was found that increasing the small droplet content $(<20 \mu \mathrm{m}$ diameter $)$ delivered the most uniform coverage over the target area.

In 2000, spray aircraft were equipped with an auto-flow system that automatically adjusted the flow rate of the control product to maintain a constant application rate as the aircraft speed changed during flight (Mickle, 2000). An auto-flow system takes information from the GPS system to determine aircraft speed relative to ground. This parameter is critical in determining application rate but is not available from standard aircraft airspeed indicators. A comparison was made on blocks sprayed with, and without, auto-flow and it was found that auto-flow technology yielded a significant reduction in application rate variability (Mickle, 2000).

The aircraft-mounted AIMMS-20 probe, an evolution of the AIMMS-10 system, was flown at different altitudes, and results were compared with SODAR (sonic detection and ranging) (Mickle, 2005). SODAR systems use sound waves to estimate the wind speed profile above ground. This study is of particular significance because it validated the ability of the AIMMS-20 probe to accurately measure wind speed and demonstrated that a single-point measurement of wind speed from a single location on the ground is insufficient to characterize the wind speed at altitude. In a project led by FPL, an AMS that incorporated real-time meteorology measurements and flight line offsetting was used on spray aircraft (Cormier, 2005; 2006; Mickle et al., 2007). The system was used to spray 8-ha triangular blocks (a difficult shape to treat), and a second set of 64-ha blocks was also sprayed with, and without, flight-line offsets. This early version of the AMS was the first operational system of its kind in agricultural/forest spraying, and results of this research demonstrated that offset spraying gave better deposit on the target area than spraying with no offset of flight lines in crosswind scenarios (Cormier, 2005, 2006; Mickle et al., 2007).

\subsection{Wind tunnel}

In parallel with AMS development, a wind tunnel facility was established to provide accurate droplet size information to the AMS. In 1975, the UNB Department of Chemical Engineering was invited by FPL to become involved in studies related to the prevention of conifer defoliation by the spruce budworm in the forests of New Brunswick. Professors Jules Picot and David Kristmanson constructed a wind tunnel specifically designed to 
measure spray droplet spectra incorporating then state-of-the-art particle size measurement systems. The 1-m diameter portable tunnel was completed in 1984. Newly emerging particle measuring systems were assessed, and in 1991, a Malvern Instruments Inc. (Malvern, UK) Fraunhofer laser diffraction spectrometer was purchased to determine droplet spectra from spray atomizers. Throughout this period, the work was coordinated with the New Brunswick Spray Efficacy Research Group (later SERG-International), which provided timely focus on the spray atomizer characterization requirements. In 2004, a partnership agreement was signed between UNB, FPL and CFS, whereby FPL became the caretaker of the wind tunnel in its new permanent location at the CFS-owned Acadia Research Forest in Noonan, NB. Extensive upgrades to the original tunnel and its new home were made at this time. In 2007, a new experimental and computational research program on aerial sprays was initiated by the UNB Department of Mechanical Engineering and FPL. The program was funded by the Natural Sciences and Engineering Research Council (NSERC) together with AIF funding to further improve the wind tunnel facility and to purchase a Sympatec (Clausthal-Zellerfeld, Germany) particle size analysis system. Since 2008, FPL and its research partners at UNB have been involved in the establishment of standards for the characterization of droplet spectra from atomizers for aerial spray applications.

\subsection{Forest protection planning systems}

Spruce budworm is the most widespread and economically important forest insect pest in eastern North America, affecting over 40 million hectares of forest at the peak of the last (1970s-1980s) outbreak. Repeated defoliation during budworm outbreaks, which typically last about 10 years, results in up to $90 \%$ growth reduction and $40-85 \%$ mortality in forests containing high quantities of spruce and balsam fir. As a result, mitigation measures such as insecticide spraying and salvage of impacted stands have been widely used during past infestations. Nevertheless, growth and mortality losses wreak havoc with forest management plans, creating considerable uncertainty about future forest conditions. Both theory and past experience imply that another spruce budworm outbreak is due across the northern forest regions of North America. The spruce budworm outbreaks of the 1970s and 1980s stimulated major insecticide spray programs as well as extensive salvage of vulnerable, dead and dying stands in some regions. It is vital that land managers responsible for forests understand potential consequences of the next spruce budworm outbreak on their wood supplies, land values and management plans. This provided the rationale for development of a forest protection planning system or PROPS. PROPS is the software component of the Spruce Budworm Decision Support System (SBWDSS) used to assist with spruce budworm population management. The concept of the SBWDSS was developed by Erdle (1989), and the software application was developed by the CFS between 1992 and 1996. From 1996 to 1999, it was operationally implemented, on a cost-shared basis with industry and the provincial government, on all 6 million hectares of forest in New Brunswick (MacLean et al., 2001, 2002). The SBWDSS provides the conceptual basis for calculating marginal timber supply benefits $\left(\mathrm{m}^{3} / \mathrm{ha}\right)$ of alternative foliage protection scenarios for each stand in a forest. PROPS software is used to implement these methods and has GIS tools to visually display SBW projected volume impacts on inventory at set time periods in the future or at the time of planned harvest; it facilitates manual spatial blocking of aerial bio-insecticide operations. PROPS allows users to determine effects of different foliage protection strategies on forest development and timber harvests (Erdle, 1989; 
MacLean et al., 2000, 2002). PROPS was implemented for all forests in New Brunswick and for test areas in four other Canadian provinces.

\section{Accuair ${ }^{\mathrm{TM}}$ - Components}

\subsection{Accuair ${ }^{\mathrm{TM}}$ aerial management system}

Over the years, a variety of fixed-wing aircraft have been developed or adapted for use in aerial pesticide application programs (see Randall, 1975; Kilroy et al., 2003; Estey, 2004; Mierzejewski et al., 2007). Air Tractor Inc. (Olney, Texas) manufactures a number of singleengine aircraft that are used for pesticide application and in fire control operations. Currently, FPL owns and operates six AT-802F (Figs. 1A and B) that can be used both for aerial application and fire suppression and an AT-802F Fire Boss that is equipped with amphibious floats, allowing it to scoop surface water from lakes and rivers near a wildfire whereas other tankers must return to the airstrip for refilling with fire-retardants.

The current version of the AMS integrates several components that make real-time spray optimization possible. The AIMMS-20 probe measures and records air velocity and direction on the wing of the aircraft (Fig. 1C). Using data from the probe and information on aircraft position and orientation, as determined by GPS, the AIMMS system calculates wind speed at the altitude of the aircraft and the direction of the wind at this level relative to the ground. In addition to wind speed and direction, the altitude of the aircraft above the target area is another important parameter in predicting the distance that spray droplets will drift once they leave the atomizers. The altitude of the aircraft is measured using radar or laser altimeters that use radio waves or laser beams, respectively, to determine the altitude of the aircraft above ground level instead of using air pressure, which determines altitude above sea level.

A light bar (AG-NAV Inc., Newmarket, ON) (Fig. 1D), mounted on the exterior and in front of the cockpit, provides the pilot with information related to spray parameters, e.g., total number of swaths, current swath, total area to be sprayed, area sprayed, application and flow rates, ground speed, course deviation indicator and obstacle warning messages.

Two types of atomizers are routinely used for aerial application: hydraulic nozzles and rotary atomizers. With hydraulic nozzles, liquid is atomized as it is forced through a small orifice. The design of the orifice determines the shape of the spray, the size of drops and ultimate usefulness of the nozzle to a given application scenario. Rotary atomizers may be wind driven or electrically powered. During flight, wind flowing over the wing drives small propeller blades of wind-driven rotary nozzles that are attached to a cylindrical wire cage (Fig. 1E). Liquid enters the cage and is broken up into droplets by centrifugal force as it hits the rotating cylinder. The droplet spectrum, generated by rotary atomizers, is determined by the physical characteristics of the spray liquid, the liquid flow rate and the speed of the rotors. The revolutions per minute (rpm) of the rotary atomizer can be adjusted by changing the pitch of the propeller blades. Boom on/off functions and adjustment of flow rates from atomizers (e.g., to compensate for aircraft speed) are made automatically using the AGFLOW system (AG-NAV Inc., Newmarket, ON) (Fig. 2). The required spray offset is calculated by a central, onboard processor based on droplet spectrum information (from wind tunnel data) and inputs from aircraft instrumentation including aircraft altitude, attitude and speed, relative to the ground and wind speed and direction at altitude (Fig. 2). 

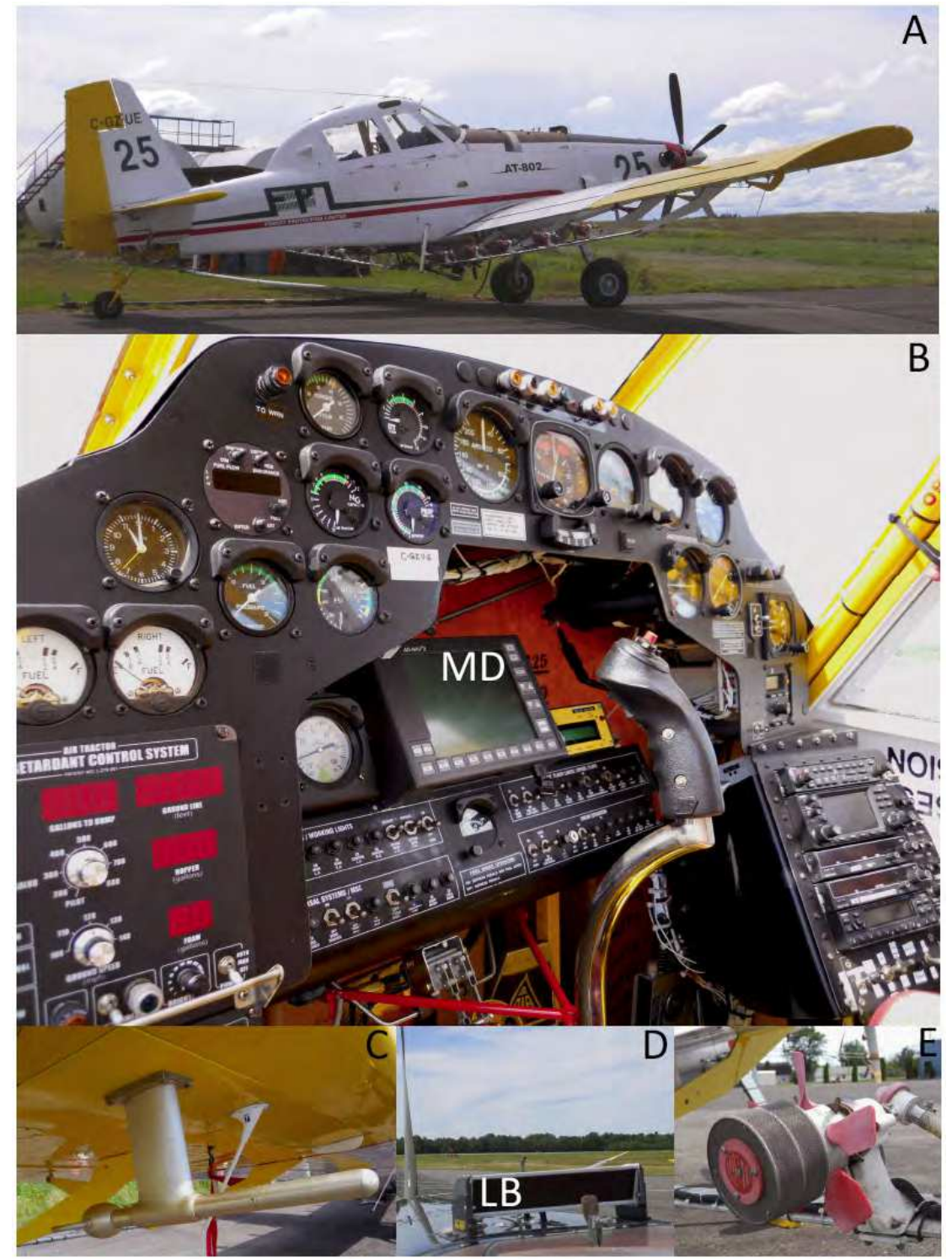

Fig. 1. Air Tractor Inc. AT-802F and components of the Accuair ${ }^{\mathrm{TM}}$ Aerial Management System. A. Forest Protection Limited (FPL) AT-802F aircraft. B. Cockpit instrument display of the FPL AT-802F shown in A. The AG-NAV differential GPS navigation and moving map display system (MD) is centrally located within the instrument display. C. The air-data probe is located on the underside of the wing near the wing-tip. D. The light bar (LB) is exterior to the cockpit on the nose cowling of the aircraft. E. A Micronair AU 4000 rotary atomizer. 


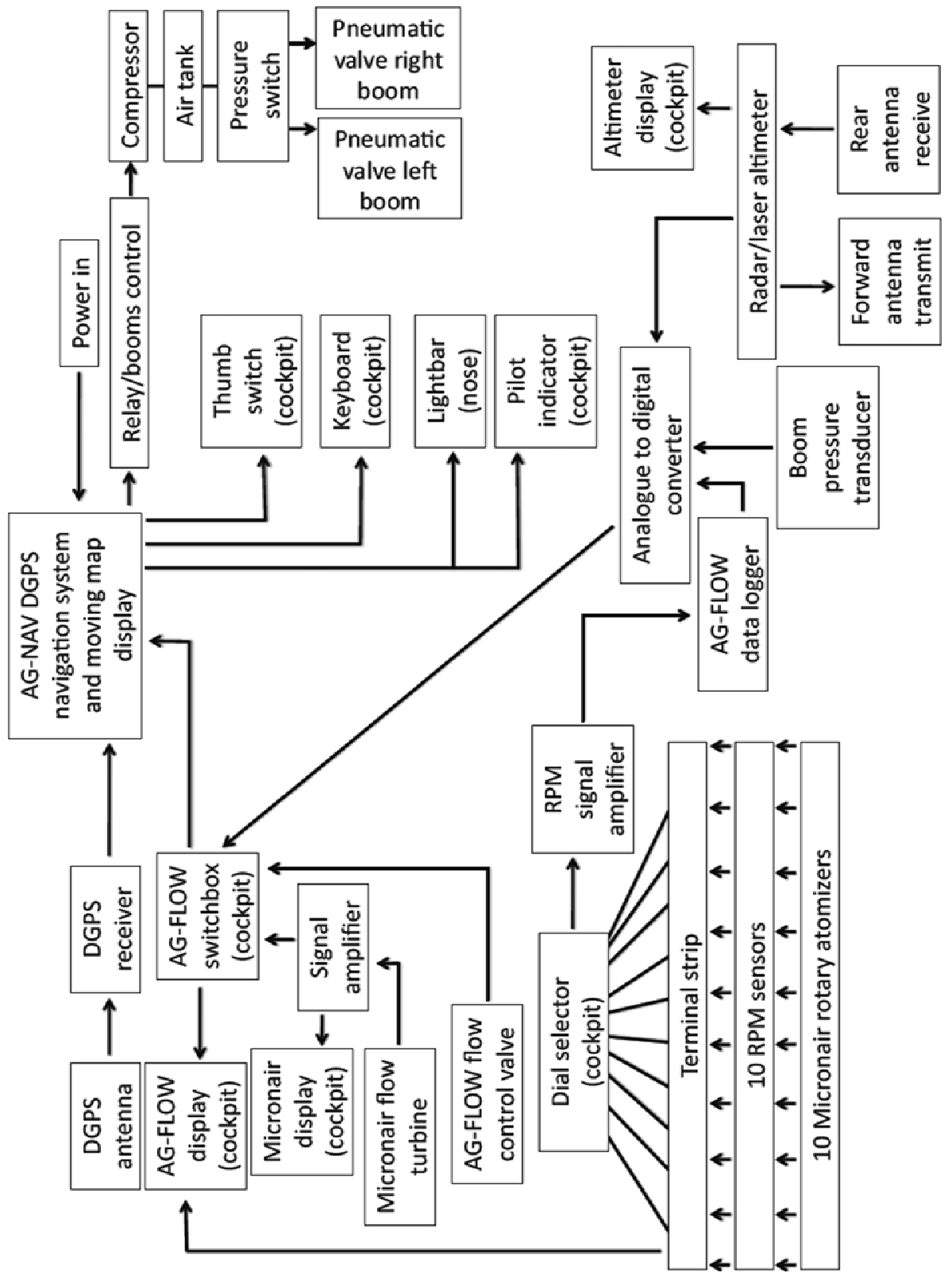

Fig. 2. Schematic diagram of the Accuair ${ }^{\mathrm{TM}}$ Aerial Management System (AMS). 

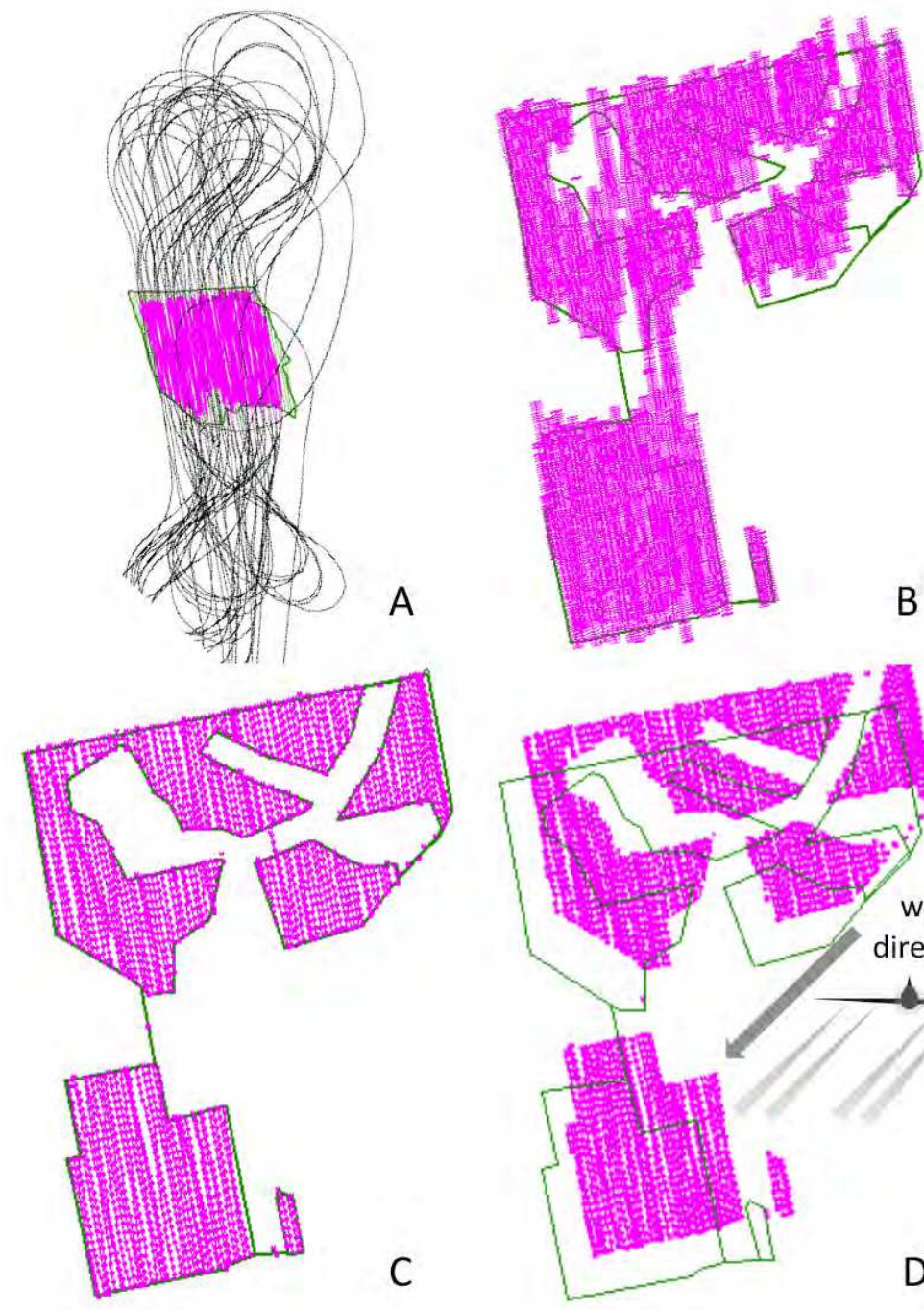

B

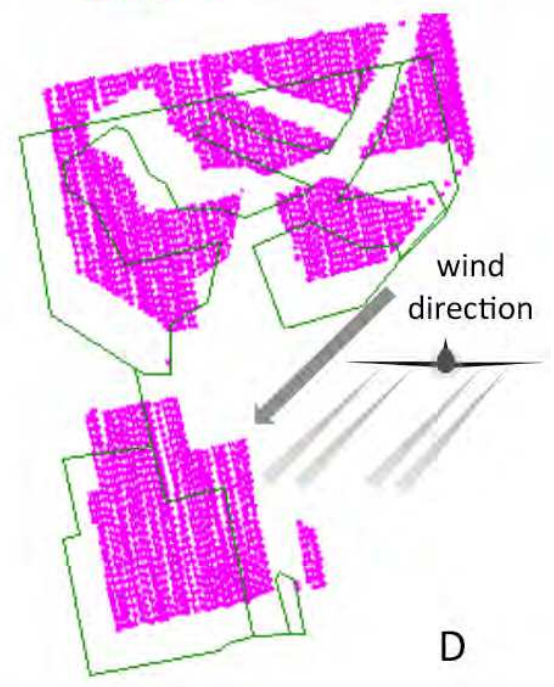

Fig. 3. Printouts of spray operation records. A. The boundaries of the block are input into the on-board computer from GPS data. Spray booms are automatically turned on as the aircraft enters the airspace over the block and turned off as the airplane exits. The black tracings are records of the aircraft flight path and the pink shows where the spray booms were turned on. B and C. Logs showing the accuracy of aerial applications when the booms were turned on (pink) and off manually by the pilot (B) and automatically by the GPS-directed autoboom controller (C) over an irregularly shaped block. D. Simulation of an optimized spray scenario over the same block as Figs. B and C, where spray lines have been off-set to allow ambient wind conditions to drift the atomized spray into the block. 
As it flies through the air, an aircraft's propulsion system and wings generate a strong aerodynamic wake. This wake extends hundreds of meters behind the aircraft and entrains much of the fine component of a spray in long horizontal vortices. The size and shape of the aircraft wake depend on aircraft wingspan, velocity and weight. The wake downwashes (moves downward) toward the ground at a typical rate of 0.3-1.0 m/s (Payne, 1995), which is much faster than the settling rate of a fine spray $(40-80 \mu \mathrm{m})$ in still air. The downwashing wake is one of the primary influences on transport of fine sprays downward into the forest canopy (Mickle \& Rousseau, 1999). With the dissipation of the aircraft wake, spray droplet trajectories are influenced by wind speed, direction and turbulence. In turn, these are influenced by air temperature and humidity, solar radiation, time of day and characteristics of the ground cover (Mierzejewski et al., 2007). Using empirical data from numerous pesticide deposition and off-target drift studies, researchers with the United States Department of Agriculture Forest Service (USDA-FS) developed the AGDISP model for use by pesticide applicators to simulate and assess spray deposition and drift. The AGDISP model has been validated and is widely used within the aerial pesticide application industry worldwide (Mierzejewski et al., 2007).

In most aerial application scenarios, treatment blocks, buffer zones and exclusion zones are established by program managers and are then entered into the AMS computer as GPS coordinates (Fig. 3A). Aircraft spray along flight lines within the block boundaries, and the boundaries act as triggers to the auto-boom system. This type of system achieves much greater accuracy than manual pilot control (Figs. 3B and 3C). Spray drift can result in significant amounts of the control product being transported and deposited outside of the target area. Procedures to optimize spray deposit were developed where the control product is released outside or at the edge of the target block so it can drift into the block (Fig. 3D) resulting in greater amounts of product actually landing within the treatment area (Mickle \& Rousseau, 1999; Cormier, 2005, 2006; Mickle et al., 2007).

\subsection{Accuair ${ }^{\mathrm{TM}}$ wind tunnel}

Spray testing is done in wind tunnels to obtain reliable control over wind speed and experimental conditions and to facilitate the use of bulky, vibration-sensitive laser dropsizing equipment that cannot easily be used to measure sprays in an operational setting. A wind tunnel enables researchers to understand how fluids are atomized under real conditions and to measure the size spectra of spray droplets produced by various atomizers. This information is essential for accurate predictions using spray drift models and for optimizing the effectiveness of sprays using modern AMS. Spray drift models are also used to guide regulatory decisions and to determine the content of pesticide labels (i.e., instructions and restrictions for use), which are of interest to operators and manufacturers alike. Knowledge of spray droplet-size spectra and the ability to calibrate atomizers to produce desired droplet-size spectra enable more accurate estimates of spray drift, increase the accuracy of flight line offset predictions, increase spray efficacy, reduce costs and reduce the environmental impact of spray programs.

The Accuair ${ }^{\mathrm{TM}}$ Wind Tunnel (Fig. 4) is owned and operated by FPL and is one of only a few wind tunnels in the world capable of testing pesticide spray products. In order to simulate aerial application conditions, the Accuair ${ }^{\mathrm{TM}}$ Wind Tunnel was designed to produce a highly uniform, low-turbulence airstream within its 1-m diameter, 5-m long test section at speeds 
of up to $300 \mathrm{~km} / \mathrm{h}$. In the wind tunnel, sprays are measured to determine the characteristics of the droplet size spectrum. These data are vital to understanding the behaviour of droplets released into the environment and in predicting the amount of spray that will be deposited on a target. Fine sprays composed primarily of small droplets are more prone to drift but provide higher efficacy in many cases, whereas coarser sprays provide better drift control but sacrifice some efficacy (Weisner, 1995). Depending on the application and the type of pesticide product used, either efficacy or drift or both may be of primary concern. It is important, therefore, to know what sort of droplet spectrum a particular nozzle or atomizer will produce under actual spray conditions. Once the performance characteristics of a nozzle or atomizer are known, the information can then be used in computer drift simulations to determine the magnitude of flight line offsets and to classify the nozzle or atomizer according to its drift potential. Drift potential is used to determine the size of buffer zones that restrict how close operators may spray near sensitive areas. Manufacturers of atomizers are motivated by regulatory authorities to incorporate drift-reducing technologies in their products that spray program operators can then use to obtain reduced buffer zone requirements. Qualification as a drift-reducing technology requires wind tunnel testing and subsequent favourable comparison of data to those obtained for standardized or reference atomizers.

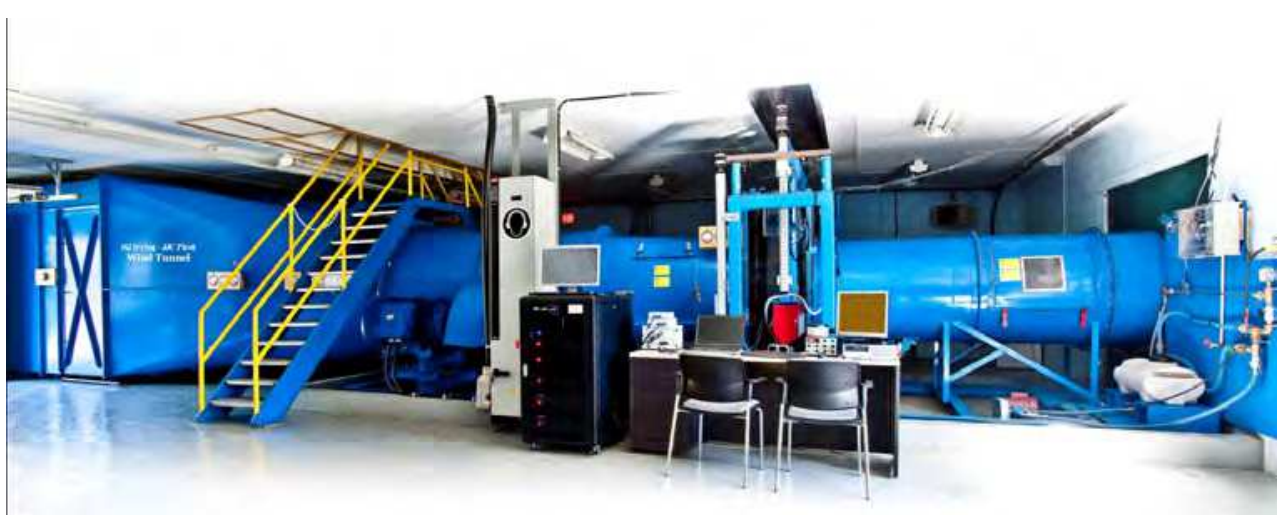

Fig. 4. The Accuair wind tunnel facility.

The measurement of droplet size spectrum is easily distorted by aerodynamic obstructions so measurements are typically made using laser drop-sizing instruments that pose no obstruction to the airflow or droplet trajectory in the wind tunnel. The most common form of expressing the droplet size distribution (DSD) for forestry and agricultural sprays is the volumetric DSD. This is represented in histograms where each histogram bar is assigned a droplet-size range, and height of the bar indicates the percentage of the emitted spray volume composed of droplets in that size range (volume fraction). The droplet size corresponding to the point where the cumulative sum of the volume fractions reaches $50 \%$ is the volumetric median drop diameter $\left(\mathrm{VMD}\right.$ or $\left.\mathrm{D}_{\mathrm{V} 50}\right)$. The $\mathrm{D}_{\mathrm{V} 50}$ provides a basic measure of spray droplet size but it is used along with other parameters such as $\mathrm{D}_{\mathrm{V} 10}$ and $\mathrm{D}_{\mathrm{V} 90}$, which are the points at which the cumulative volume fraction sum reaches $10 \%$ and $90 \%$ of the total, respectively, indicating how widely the spray droplet sizes are distributed about the median. 


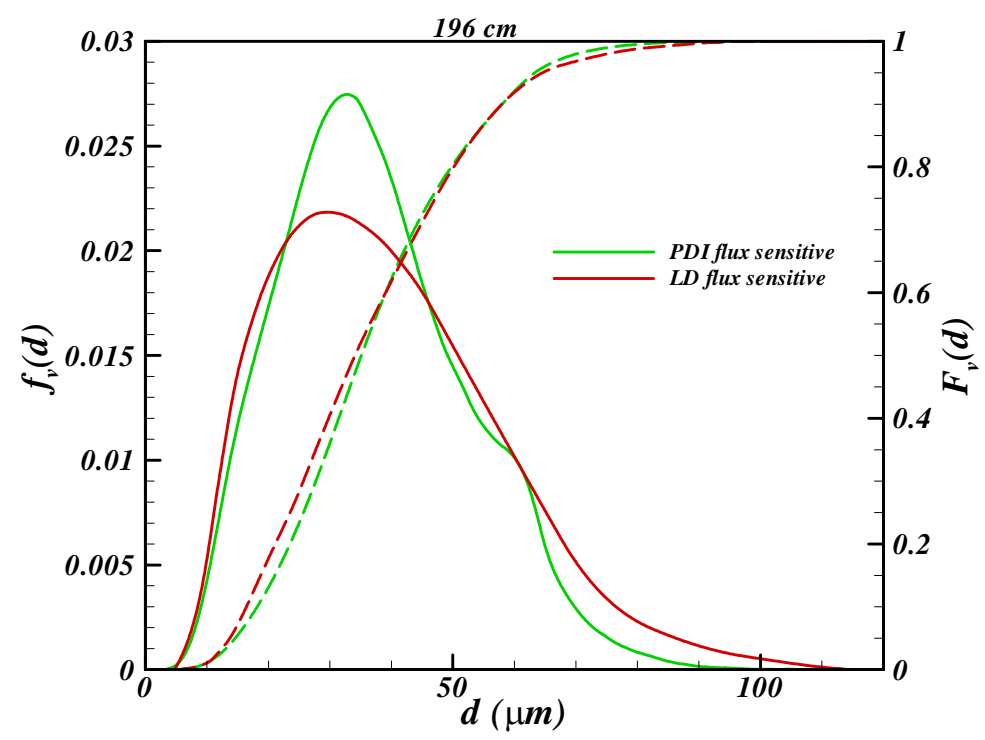

Fig. 5. Sample droplet size distribution (DSD) from the laser diffraction (LD) system and phase Doppler instrument (PDI).

The Accuair ${ }^{\mathrm{TM}}$ Wind Tunnel employs two instruments to characterize emitted droplet spectra. The laser diffraction (LD) system provides rapid measurements of a DSD across the entire plume that is based on droplet concentration and can be applied to opaque droplets, making it a good choice for characterization of pesticide spray products (Fig. 5). The phase Doppler (PD) system provides measurements of a DSD that are based on droplet flux and measurements of droplet velocity, which is vital for data interpretation. For the DSD results to be meaningful, sampling must take into account the flux (flow rate) of droplets through the measurement location because droplet flux rather than concentration is correlated to spray coverage and deposition The requirement to transform LD measurements to flux, based DSD poses a significant problem for spray characterization in wind tunnels where droplet velocity measurements are not available. The Accuair ${ }^{\mathrm{TM}}$ Wind Tunnel facility, with its complete set of instrumentation, has played a central role in developing guidelines to address issues related to LD spray measurement. These guidelines were compiled in a standard testing methodology submitted to the American Society for Testing and Materials (ASTM) in 2011.

Research into full physics computational fluid dynamic (CFD) modelling (Figs. 6 and 7) can provide a means of examining spray development beyond the wind tunnel environment. Typically, CFD models require validation and calibration using a set of measurements from limited numbers of test cases. For example, CFD models validated against measurements of turbulent droplet transport in the wind tunnel may be extended to simulations of the near wake of the aircraft (10-250 m downwind) and ultimately to predict transport far beyond the wake of the aircraft. These are long-term goals of the present computational research program of UNB and FPL. 


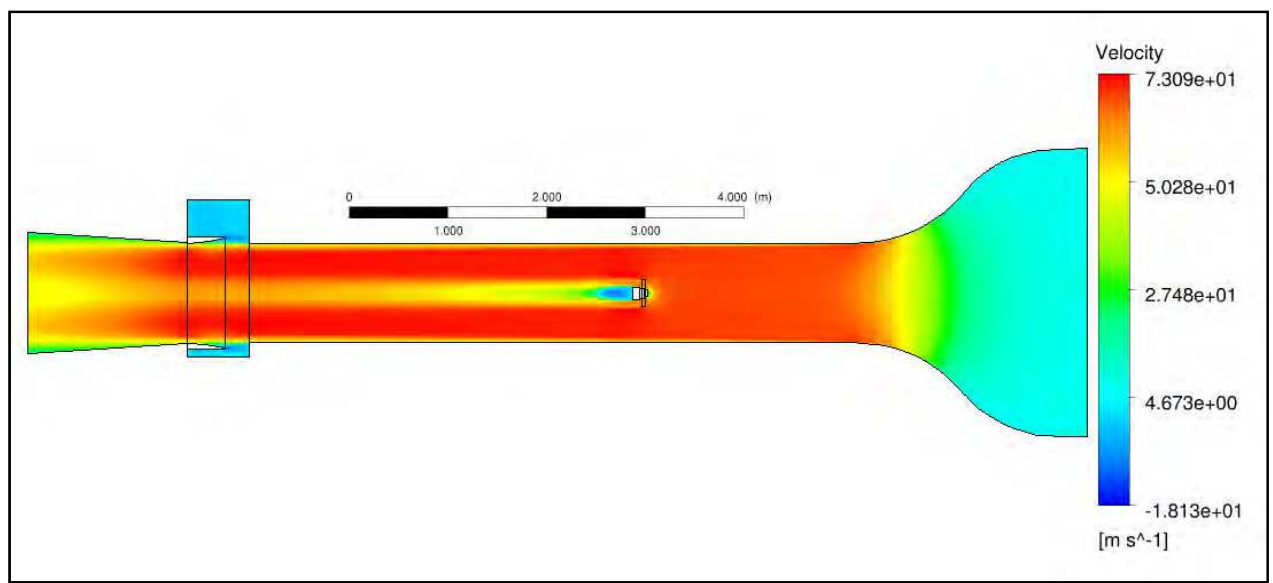

Fig. 6. Computational fluid dynamic (CFD) simulation of the axial velocity field in the wind tunnel.

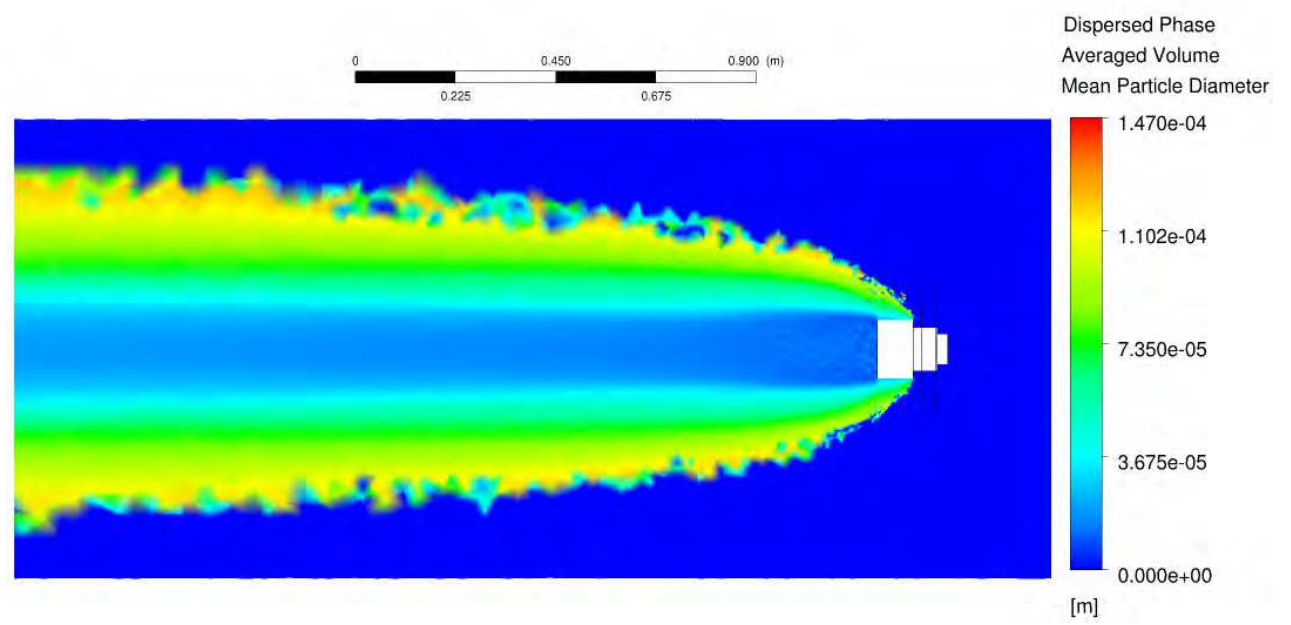

Fig. 7. Computational fluid dynamic (CFD) simulation of the dispersed droplet phase in the wind tunnel.

\subsection{Accuair ${ }^{\mathrm{TM}}$ ForPRO}

The Accuair ${ }^{\mathrm{TM}}$ Forest Protection Optimization System (ForPRO) is a new software package that allows integration between forest management planning and optimization models and underlying tree impact information derived from pest management decision support tools. ForPRO includes defoliation impact modelling data for a number of insect species, including spruce budworm, jack pine budworm (Choristoneura pinus), eastern hemlock looper (Lambdina fiscellaria fiscellaria) and balsam fir sawfly (Neodiprion abietis). Potential users of ForPRO include government agencies responsible for forest protection and maintenance of sustainable timber supplies, forest companies that conduct insecticide 
spray programs, and private landowners interested in quantifying vulnerability of their forest to insects and prioritizing ways to reduce future losses. Proactive assessment of vulnerability to, and implications of, current or possible future insect outbreaks is essential to develop and justify effective policies, response strategies and appropriate infrastructure before these events unfold. ForPRO can assist land managers in quantifying marginal benefits of protecting forest stands against insect defoliation (e.g., in terms of timber volume in $\mathrm{m}^{3} /$ ha or value as $\$ / \mathrm{ha}$ ). Protection cost:benefit analyses can be conducted using existing forest inventory and insect monitoring data in combination with forest management planning models to project the effects of foliage protection strategies on forest development and forest values.

ForPRO is composed of a number of specialized tools that allow users to simulate insect impacts on trees, stands, and forests. These tools leverage stand growth modelling capabilities from the FORUS Simulation Framework (FORUS Research, Fredericton, NB) and allow forest impact analyses to be conducted with existing strategic forest management optimization models (Remsoft Spatial Planning System; Remsoft, Inc. Fredericton, NB). These capabilities permit efficient exploration of cost-effective foliage protection or salvage scenarios.

ForPRO tools can be divided into those used in estimating stand impacts for strategic forest impact analysis (non-spatial tools) and those used for optimal spatial design of operational spray blocks (spatial tools). Non-spatial tools can be used to calibrate and implement SBWDSS. In 2009, ForPRO was used by the New Brunswick Department of Natural Resources (NBDNR) to estimate timber supply impacts on all Crown lands in New Brunswick for a variety of spruce budworm outbreak and foliage protection scenarios. These results were also used in the analyses of the effects of spruce budworm outbreaks on direct and indirect economic benefits from forests (Chang et al., 2012). The generalized framework of the SBWDSS has also been applied to insects other than spruce budworm. ForPRO was used to calibrate and predict timber supply impacts of balsam fir sawfly and hemlock looper defoliation scenarios in Newfoundland, Canada (Iqbal et al., 2011c), and NBDNR subsequently used ForPRO to help prioritize protection treatments for a localized balsam fir sawfly outbreak in New Brunswick.

Spatial tools include the 'Blocking Assistant' and ArcGIS extensions to allow forest protection priority maps (expected volume loss/area) to be spatially blocked for aerial application of biological insecticides. The Blocking Assistant uses meta-heuristic optimization algorithms and information about aircraft cost and flight constraints to help users search for blocking arrangements that increase the cost:benefit ratio of an aerial protection program.

The ForPRO insect decision support framework includes several software tools and steps to translate measured or predicted annual defoliation levels into estimated tree, stand and forest volume impacts. Some of these tools can be used to calculate tree growth reduction and survival from annual defoliation estimates for specific insect pest species or to classifying stands based on host tree species susceptibility to defoliation by certain insect species. Other tools do not include input of insect-related data and are used for such functions as averaging projected stand volume impacts according to stand-type classes to build the Stand Impact Matrix (MacLean et al., 2001).

ForPRO provides three software tools to assist with stand-level impact modelling and compilation for use in forest-level impact analyses. 


\subsubsection{Stand model multiplier builder}

Modelling insect effects on stand dynamics within ForPRO is typically conducted using the stand development model, STAMAN (New Brunswick Growth and Yield Unit [NBGYU], 2004) to forecast defoliation impacts on merchantable volume (Erdle \& MacLean, 1999), estimate salvageable volume (Hennigar et al., 2007) and determine changes to stand harvest timeframes. For spruce budworm and jack pine budworm, ForPRO facilitates modelling via the Stand Model Multiplier Builder. This tool converts user-defined estimates of annual defoliation by species into periodic 5-year mean estimates weighted by the proportion of total foliage mass by age class on a healthy balsam fir crown (MacLean et al., 2001), and then uses 5-year periodic defoliation and defoliation-impact relationships to calculate percentage tree growth or survival multiplier values relative to undefoliated conditions. ForPRO has pre-defined defoliation-damage multiplier files derived for spruce budworm (Erdle \& MacLean, 1999) and jack pine budworm (Iqbal et al., 2011b), but users can develop their own damage multiplier files for other insects or adjust existing ones.

The FORUS Simulation Framework can be used to execute stand development models such as STAMAN with, or without, defoliation-impact multiplier commands for one or thousands of forest inventory plots. The Simulation Framework also provides a means to summarize tree-level projection output files (tree lists or stand tables) into other measures such as merchantable volume over time by species or species groups. Summarized reports can be output to a database table or text file. Although ForPRO, STAMAN and the FORUS Simulation Framework can all work together, they can also act as stand-alone programs.

\subsubsection{Stand composition classifier}

The Stand Composition Classifier tool provides a forest stand-type class link between stand impacts and forest inventory attributes. Classes are generally derived based on stand species composition, site, development stage (young, mature, old), canopy density, historical silviculture regime and geographic region. Similar classification logic is used to aggregate plot-level impact forecasts into stand-type classes in order to minimize projected volume impact variance within types. Typically, stand impacts vary the most by species composition and age because these attributes, in general, most significantly influence tree defoliation - damage relationships (MacLean et al, 2001; Hennigar et al., 2007, 2008; Iqbal et al., 2010, 2011a, 2011b).

The ForPRO Stand Composition Classifier tool facilitates the classification of percent tree species composition information from a GIS layer or yield table stored in a database into stand-type impact classes. The stand-type impact classes calculated for each record are written back to the same database in a single column, which can then be manually merged with other forest classification attributes common to both the inventory plots and forest estate model or GIS. The combination of criteria used to classify stands is left up to the user. The species classification algorithm and species information required also depend on the insect species of concern.

\subsubsection{Stand impact matrix builder}

Once the stand impact class link has been established between data sets, differences (percent reductions) between volume projections by tree species and plot with, and without, 
defoliation are calculated using the ForPRO Stand Impact Matrix Builder. The Stand Impact Matrix Builder tool also averages impact multipliers by grouping plots into stand-type impact classes. Model outputs or key performance indicators can be any stand measure (e.g., carbon, wildlife habitat index), but are typically timber volume over time by tree species. Using these data, the Stand Impact Matrix Builder quantifies relative differences between the base (undefoliated) and defoliated stand growth, by scenario, stand and time period:

$$
\% \text { volume change }=\text { defoliation volume } / \text { base volume } \times 100
$$

Once stand-level impacts are calculated, the Stand Impact Matrix Builder automatically averages impacts for each scenario and stand measure by stand impact class and period. Options allow for some degree of control of this averaging algorithm. If stand measures of dead volume are included with live volume estimates, additive (insect-caused) or total salvageable volume relative to base live volume yields can be calculated using the Stand Impact Matrix Builder. The resulting stand-type class, salvageable volume can be referenced against base-yield tables in the forest estate model to estimate forest-level salvageable volume available over time. The Stand Impact Matrix is essentially a large lookup table of time-dependent volume impact multipliers by defoliation scenario, tree species and stand impact class that can be readily linked to forest inventory records and yield tables stored in a relational database. Once these information sources are linked, calculations of projected volume impacts at time of planned harvest or forest inventory reduction caused by a defoliator.

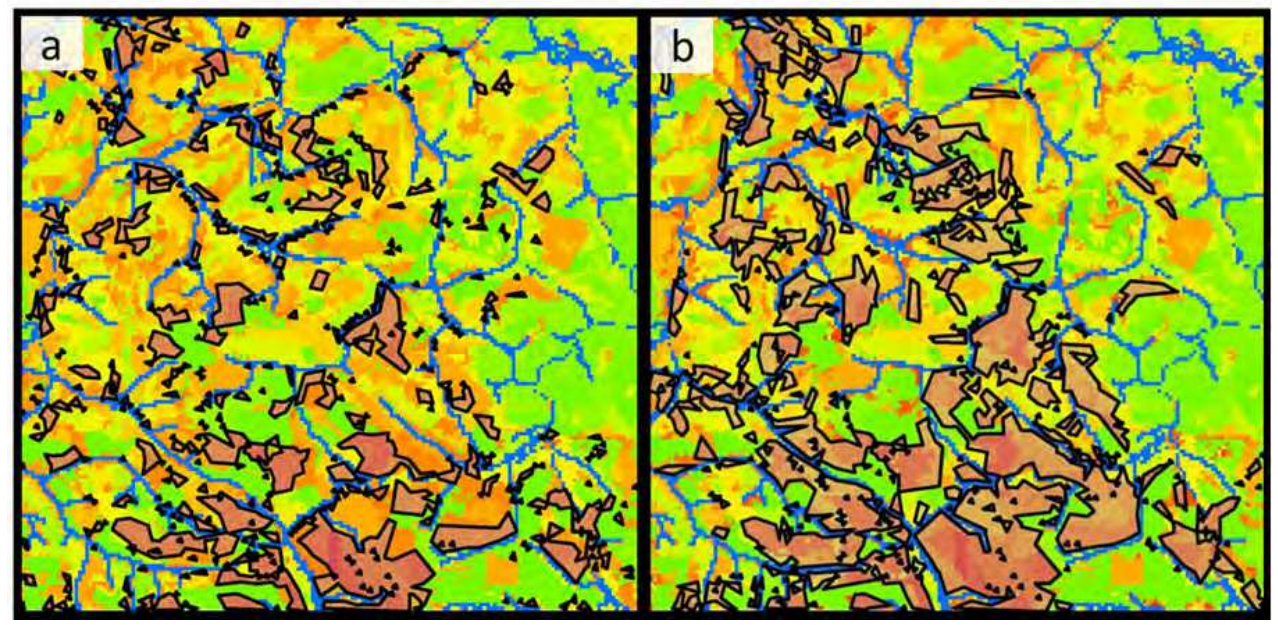

Fig. 8. Comparison of two $\$ 1$ million aerial foliage protection programs scheduled for: a) highest volume loss protected first (non-spatial), and b) optimal spatial blocking of aerial operations to maximize the economic cost:benefit ratio of individual block flight plans. Each grid cell is 1 ha.

For land managers who use the Remsoft Spatial Planning System (RSPS; Remsoft, 2010), much of the database work described above can now be avoided by using the ForPRO plugin for RSPS. The ForPRO plug-in allows yield tables in the RSPS forest estate model to be classified and linked to the Stand Impact Matrix with only minor changes to the RSPS 
model. This integration allows users to utilize the management optimization capabilities of RSPS with yield table impact information produced by ForPRO. The ForPRO framework allows for more efficient communication and integration between existing strategic forest planning optimization models and pest impact information. This can ultimately extend and accelerate implementation of the impact analysis methods used in the SBWDSS (Erdle, 1989; MacLean et al., 2001). ForPRO has also been expanded to allow for the automated spatial blocking of aircraft flight plans to optimize the net cost:benefit ratio of any foliage protection program (Fig. 8). The blocking algorithm blends strategic-level information on land value with industry-calibrated aircraft operational constraints and costs. A blocking cost algorithm that considers aircraft flight plan and spray constraints was refined with input from FPL and the Pest Management Branch of NBDNR.

\section{Concluding remarks}

The funding provided by the ACOA AIF and NSERC and the additional financial contributions of the research partners have allowed for the consolidation of a number of independent research efforts that has resulted in the Accuair ${ }^{\mathrm{TM}}$ suite of aerial application technologies and services (AMS, wind tunnel, and ForPRO). Additionally, these funds and this partnership have advanced the development of baculovirus-based biopesticides for use in forestry (not presented here). The results of this 5-year research project have established Canada as a leader in the development and practical use of aerial application technologies and decision support so that pesticides can be applied accurately, effectively and with minimal impact on the environment.

\section{Acknowledgements}

The financial support provided by the Atlantic Canada Opportunities Agency - Atlantic Innovation Fund, The Natural Sciences and Engineering Research Council of Canada, the Canadian Forest Service (Natural Resources Canada), the membership of SERGInternational, AG-NAV Inc., BioAtlantech, Forest Protection Limited, Sylvar Technologies Inc. and the University of New Brunswick is gratefully acknowledged. A great number of people assisted in this project, and their contributions are also gratefully acknowledged. We thank C. Riley and E.G. Kettela for their reviews of an earlier draft of the manuscript.

\section{References}

Blais, J.R., Benoit, P., and Martineau, R. 1975. Aerial control operations against the spruce budworm in Quebec, In: Aerial Control of Forest Insects in Canada, M.L. Prebble (Editor), pp. 113-125. Department of the Environment, Ottawa, Canada.

Chang, W-Y., Lantz, V.A., Hennigar, C.R., and MacLean, D.A. 2011. Benefit-cost analysis of spruce budworm (Choristoneura fumiferana Clem.) control: incorporating market and non-market values. Journal of Environmental Management 93: 104-112.

Cormier, G. 2005. An aerial management system. SERG-International / Canadian Forest Service Workshop: Forest pests and sustainable forest management in Canada 1994-2014, p. 115. Fredericton, NB, Canada, February 7-10, 2005.

Cormier, G. 2006. Aerial application to PROPS polygons. SERG-International / USDA Forest Service Workshop, pp. 206-207, Banff, AB, Canada, February 13-16, 2006. 
Davies, D. 1994. Some operational parameters for consideration in aerial pesticide applications and their potential for future development. CAPCO Technical Session: Overview of Spray Drift and Deposit. Canadian Association of Pesticide Control Officials (CAPCO) Annual Meeting, pp. 53-55, ISBN 0-662-22637-2, Ottawa, ON, Canada, October 25, 1994.

Erdle, T.A. 1989. Concept and practice of integrated harvest and protection design in the management of eastern spruce fir forests. Ph.D. Dissertation, University of New Brunswick, Fredericton, NB, Canada. 161 pp.

Erdle, T.A., and MacLean, D.A. 1999. Stand growth model calibration for use in forest pest impact assessment. Forestry Chronicle 75: 141-152.

Estey, R.H. 2004. Canadian use of aircraft for plant protection. Phytoprotection 85: 7-12.

Flieger, B.W. 1964. A new method for guiding spray aircraft. Department of Forestry, Forest Entomology and Pathology Branch, Bi-monthly Progress Report 20: 2-4.

Hennigar, C.R., MacLean, D.A., Porter, K.B., and Quiring D.T. 2007. Optimized insecticide application and harvest planning to reduce volume losses to spruce budworm. Canadian Journal of Forest Research 37: 1755-1769.

Hennigar, C.R., MacLean, D.A., Quiring, D.I., and Kershaw, J.A. Jr. 2008. Differences in spruce budworm defoliation among balsam fir and white, red, and black spruce. Forest Science 54: 158-166.

Howse, G.M. and Sippell, W.L. 1975. Aerial control operations against the spruce budworm in Ontario, In: Aerial Control of Forest Insects in Canada, M.L. Prebble (Editor), pp. 8593, Department of the Environment, Ottawa, Canada.

Iqbal, J., MacLean, D.A., and Kershaw, J.A. 2010. Quantitative impacts of hemlock looper defoliation on growth and survival of balsam fir, black spruce and white birch in Newfoundland, Canada. Forest Ecology and Management 261: 1106-1114.

Iqbal, J., MacLean, D.A., and Kershaw, J.A. 2011a. Balsam fir sawfly defoliation effects on survival and growth quantified from permanent sample plots and dendrochronology Forestry. 84: 349-362

Iqbal, J., Amos-Binks L.J., and MacLean, D.A. 2011b. Meta-analysis of growth and mortality response of jack pine to jack pine budworm defoliation. Canadian Journal of Forest Research (under review).

Iqbal, J., Hennigar C.R., and MacLean, D.A. 2011c. Contrasting insecticide protection versus forest management approaches to reducing balsam fir sawfly and hemlock looper damage. Agricultural and Forest Entomology In press.

Kilroy, B., Karsky, D., and Thistle, H. 2003. Aerial application equipment guide 2003. FHTET-2003, USDA-FS, Morgantown, WV.

MacLean, D.A., K.B. Porter, W.E. MacKinnon, and K.P. Beaton. 2000. Spruce Budworm Decision Support System: lessons learned in development and implementation. Computers and Electronics in Agriculture 27: 293-314.

MacLean, D.A., Erdle, T.A., MacKinnon, W.E., Porter, K.B., Beaton, K.P., Cormier, G., Morehouse, S., and Budd, M. 2001. The spruce budworm decision support system: forest protection planning to sustain long-term wood supply. Canadian Journal of Forest Research 31: 1742-1757.

MacLean, D.A., Beaton, K.P., Porter, K.B., MacKinnon, W.E., and Budd, M.G. 2002. Potential wood supply losses to spruce budworm in New Brunswick estimated using the spruce budworm decision support system. The Forestry Chronicle 78: 739-750. 
Mierzejewski, K., Reardon, R.C., Thistle, H., and Dubois, N.R. 2007. Conventional application equipment: aerial application. In: Field Manual of Techniques in Invertebrate Pathology, pp. 99-126, L.A. Lacey and H.K. Kaya (Editors), Springer, ISBN 978-1-4020-5931-5, Dordrecht, The Netherlands.

Mickle, R. 1998. Developing effective strategies for managing current and new epidemics of spruce budworm. Report (unpublished) to Forest Protection Limited, 100 pp. Lincoln, NB, Canada.

Mickle, R. 1999. Optimization trials for insecticide spraying into small blocks, Murdochville results, Report (unpublished) to Forest Protection Limited, 36 pp. Lincoln, NB, Canada.

Mickle, R. 2000. An evaluation of the Auto-Cal flow controller. Report (unpublished) to Forest Protection Limited, 15 pp. Lincoln, NB, Canada.

Mickle, R. 2005. Evaluation of the AIMMS-20 airborne meteorological package. Report (unpublished) to Forest Protection Limited, 19 pp. Lincoln, NB, Canada.

Mickle, R., and Robinson, A.G. 1991. An evaluation of a radar altimeter for forestry spraying. Report (unpublished) to Forest Protection Limited, 6 pp. Lincoln, NB, Canada.

Mickle, R.E. and Rousseau, G. 1999. Optimization trials for insecticide spraying into small blocks - Murdochville results. Spray Efficacy Research Group (SERG) Report \#1998/04, 37 pp.

Mickle, R., Rousseau, G., and Cormier, G. 2007. Optimized aerial application to PROPS forest polygons. SERG-International Workshop, pp. 206-207, Quebec, QC, Canada, February 12-14, 2007.

Miller, C.A. and Kettela, E.G. 1975. Aerial control operations against the spruce budworm in New Brunswick. In: Aerial Control of Forest Insects in Canada, M.L. Prebble (Editor), pp. 94-112 Department of the Environment, Ottawa, Canada.

New Brunswick Growth and Yield Unit. 2004. STAMAN 5.5 user's guide, 15 pp, New Brunswick Department of Natural Resources, Fredericton, NB, Canada.

Payne, N.J. 1995. Spray dispersal, deposition, and assessment. In: Forest Insect Pests in Canada, J.A. Armstrong and W.G.H. Ives (Editors), pp. 465-478, Natural Resources Canada, Canadian Forest Service, ISBN 0-660-15945-7, Ottawa, Canada.

Picot, J. 1994. Deposit and drift in aerial spraying. CAPCO Technical Session: Overview of Spray Drift and Deposit. Canadian Association of Pesticide Control Officials (CAPCO) Annual Meeting, pp. 33-52, ISBN 0-662-22637-2, Ottawa, ON, Canada, October 25, 1994.

Randall, A.P. 1975. Application technology. In: Aerial Control of Forest Insects in Canada, M.L. Prebble (Editor), pp. 34-55, Department of the Environment, Ottawa, Canada.

Remsoft Inc. 2010. Remsoft Spatial Planning System. Woodstock 2010.5 user guide, Remsoft Inc., Fredericton, NB, Canada.

Riley, C. 1994. Factors affecting the deposition and drift of pesticide sprays. CAPCO Technical Session: Overview of Spray Drift and Deposit. Canadian Association of Pesticide Control Officials (CAPCO) Annual Meeting, pp. 13-24, ISBN 0-662-22637-2, Ottawa, ON. October 25, 1994.

Weisner, C.J. 1995. Review of the role of droplet size effects on spray efficacy. In: Forest Insect Pests in Canada, J.A. Armstrong and W.G.H. Ives (Editors), pp. 493-496, Natural Resources Canada, Canadian Forest Service, ISBN 0-660-15945-7, Ottawa, Canada. 


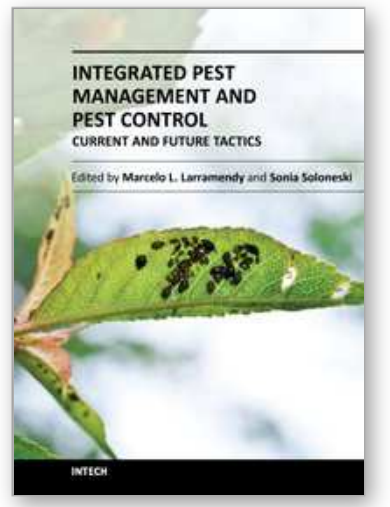

\author{
Integrated Pest Management and Pest Control - Current and Future \\ Tactics \\ Edited by Dr. Sonia Soloneski
}

ISBN 978-953-51-0050-8

Hard cover, 668 pages

Publisher InTech

Published online 24, February, 2012

Published in print edition February, 2012

Integrated Pest Management is an effective and environmentally sensitive approach that relies on a combination of common-sense practices. Its programs use current and comprehensive information on the life cycles of pests and their interactions with the environment. This information, in combination with available pest control methods, is used to manage pest damage by the most economical means and with the least possible hazard to people, property, and the environment.

\title{
How to reference
}

In order to correctly reference this scholarly work, feel free to copy and paste the following:

Ian M. McLeod, Christopher J. Lucarotti, Chris R. Hennigar, David A. MacLean, A. Gordon L. Holloway, Gerald A. Cormier and David C. Davies (2012). Advances in Aerial Application Technologies and Decision Support for Integrated Pest Management, Integrated Pest Management and Pest Control - Current and Future Tactics, Dr. Sonia Soloneski (Ed.), ISBN: 978-953-51-0050-8, InTech, Available from:

http://www.intechopen.com/books/integrated-pest-management-and-pest-control-current-and-futuretactics/advances-in-aerial-application-technologies-and-decision-support-for-integrated-pest-management

\section{INTECH}

open science | open minds

\section{InTech Europe}

University Campus STeP Ri Slavka Krautzeka 83/A 51000 Rijeka, Croatia Phone: +385 (51) 770447

Fax: +385 (51) 686166 www.intechopen.com

\section{InTech China}

Unit 405, Office Block, Hotel Equatorial Shanghai No.65, Yan An Road (West), Shanghai, 200040, China 中国上海市延安西路65号上海国际贵都大饭店办公楼405单元 Phone: +86-21-62489820

Fax: +86-21-62489821 
(C) 2012 The Author(s). Licensee IntechOpen. This is an open access article distributed under the terms of the Creative Commons Attribution 3.0 License, which permits unrestricted use, distribution, and reproduction in any medium, provided the original work is properly cited. 